

\section{A estética da comunicação nos videogames: a relação designer-jogador}

\author{
Aesthetics of communication in \\ videogames: the relationship between \\ designer and gamer
}

\section{Resumo}

Este artigo apresenta resultados de pesquisa sobre a experiência estética na relação entre o jogador e os videogames. A pesquisa foi conduzida a partir da experiência do pesquisador-jogador em cotejo com a pesquisa bibliográfica dos temas que dizem respeito à ludicidade, à narrativa, à semiose e à estética da comunicação, tendo como objeto de estudo a comunicação entre o designer e o jogador durante o ato de jogo. Foi constatado que a relação entre o videogame e o gamer é mediada por uma semiose que estabelece uma estética comunicacional entre as partes envolvidas nesta relação. Verificou-se também que as mecânicas de jogo promovem estéticas comunicacionais que conversam com a inteligência cognitiva humana, levando a uma comunicação plena entre os conceitos de design implementados em um jogo e o campo de percepção pessoal do jogador.

\section{Palavras-chave}

Estética da comunicação; videogames; design de games; semiose; percepção.

\section{Abstract}

This article presents research results on the aesthetic experience in the relationship between the player and video games. The investigation was conducted from the experience of the player-researcher in comparison with literature on issues that concern ludology, narrative, semiosis and the aesthetics of communication, with the research object being the relationship between the game and the player during gameplay. It was found that the relationship between the game and the gamer is mediated by a semiosis that establishesanaestheticcommunication between the two parts studied in this relationship. It was also found that the game mechanics promote communication aesthetics that deals with human cognitive intelligence, leading to a full communication process between design concepts implemented in a game and the player's personal perception field.

\section{Keywords}

Aesthetics of communication; videogames; game design; semiosis; perception. 
A evolução tecnológica dos games acompanhou uma demanda de mercado para produtos com mais sofisticação, exigida pelos jogadores nas últimas duas décadas, mas também foi fruto de um amadurecimento artístico por parte das empresas desenvolvedoras dos jogos que passaram a incluir em suas equipes desenvolvedores que já haviam crescido jogando os primeiros games. Estes primeiros jogos, lançados no começo do boom dos videogames na década de 1970, possuíam natureza competitiva e se focavam em pequenas sessões de jogos, normalmente em arcades dispostos em locais públicos, sem muitas pretensões artísticas ou narrativas, e mais focado na ação momentânea e divertimento rápido e superficial. Posteriormente, a tendência dos jogadores a comprar máquinas de jogo (consoles) voltados para o uso doméstico causou uma mudança no desenvolvimento de jogos. Agora os jogadores contavam com mais tempo para apreciar um jogo, e o mesmo poderia ser analisado e arquivado, assim como uma obra de arte tradicional, como um livro ou filme.

Pessoas com backgrounds variados de outras áreas da produção artística e técnica, como o diretor de jogos japonês Hideo Kojima, criador de Metal Gear (Konami, 1987), formado em cinema, para citar um exemplo, ou ainda o artista plástico francês Éric Chahi, criador de Out of This World (Delphine Soft., 1991), visaram proporcionar experiências mais complexas ao público cada vez mais exigente dos games. Por sua vez, este público consumidor mostra cada vez mais interesse na convergência narrativa dos videogames com mídias mais consolidadas artisticamente, como o cinema, a literatura e as artes plásticas.

Neste artigo, abordamos estes dois agentes que estiveram em comunicação indireta através da cul- tura dos games, o jogo (projetado pelos game designers, conhecidos também como desenvolvedores) e o jogador (o público consumidor dos games), que, por meio da estética presente nos elementos do jogo e a percepção, formam uma estética comunicacional mediada por signos. Detalharemos as mecânicas narrativas implementadas nos games, as dinâmicas criadas para interação dos seus jogadores com o mundo de jogo e as cognições percebidas dentro destes processos comunicativos.

Videogames se tornaram um novo meio tecnológico e interativo de transmissão de histórias. Mais do que isso, eles são um novo processo comunicativo, tão completo e efetivo esteticamente, quanto os meios comunicacionais que os precedem. No entanto, para serem completos, games necessitam do seu jogador, e este inteator é um agente dessa comunicação, não somente um receptor passivo. O seu campo de percepção estética é tão importante quanto a estética presente no game, e a interação desses dois universos cognitivos é o objeto deste artigo dentro de uma área relativamente nova, mas de grande potencial para exploração científica.

\section{A estética dos games como}

\section{processo comunicativo}

O sentido usual da palavra estética remete ao belo, ao sublime, geralmente ligado às artes visuais, mas também percebida em processos de variadas origens. Conforme Luís Mauro Sá Martino (2007), a estética tradicional remete ao ramo da filosofia que trata da arte. "Estudar estética é estudar as manifestações e formas do belo, o que diferencia o belo natural do belo artístico e mesmo, em certos casos, uma história dos componentes de cada escola artística" (Martino, 2007, p. 13). Ele explica que o uso da palavra pela filosofia no sentido de estudo da arte remonta a Hegel (Bras, 1990):

O filósofo de lena, em suas palestras introdutórias sobre arte, toma a palavra "estética" como o que se entende hoje por teoria da arte, procurando explicar o desenvolvimento das formas artísticas desde a Grécia Clássica até seu tempo presente, o século XIX, como uma progressiva manifestação do espírito rumo ao Absoluto. A "estética", nesse sentido, seria o estudo dessas manifestações em suas variadas formas em seu caminho rumo à beleza (Martino, 2007, p. 13, grifo do autor).

O uso da palavra modificou-se e virou referência, nos dias de hoje, à estética da imagem atrelada a produtos audiovisuais. A parte estética de um filme, por exemplo, pode remeter às suas técnicas visuais, iluminação, maquiagem, qualidade de transmissão, além de outros aspectos que influenciam no sentido humano primário da visão. No entanto, Martino ressalta que mesmo na Grécia o termo já possuía uma profundidade maior da que a que Ihe é atribuída hoje. Utilizada no sentido de estudo do belo artístico, a aisthesis grega "tratava de designar com isso um tipo específico de sensação, entendida como a impressão causada nos sentidos - e portanto na mente - pelos objetos exteriores" (Martino, 2007, p.14). Ele ainda acrescenta que a estética seria "o instante no qual o sujeito e objeto se ligam em uma relação comunicacional". (Martino, 2007, p. 14).

Conforme Martino, a palavra grega que deu origem ao termo, aisthesis, significa "sensibilidade", no sentido de sentir, mas também em um sentido mais profundo, o de comunicar algo através destes sentidos. O autor define a estética da comunicação como: 
Uma atividade dos sentidos relacionada, no entanto, com as possibilidades mentais de atividade, é esse o conceito pensado quando se fala em uma Estética da Comunicação. Não se trata do estudo da obra de arte, ou dos determinados elementos artísticos das mensagens de mídia, mas pensar as relações entre os meios de massa e o indivíduo como um exercício de sensibilidade e produção, uma aisthesis geradora de uma poiesis (Martino, 2007, p. 11).

A poiesis (palavra grega que é raiz semântica da palavra "poesia") a que o autor se refere é a poética que a estética comunicacional envolve na transmissão da informação através da recepção individual. É o "perceber, no sentido de criar a razão para o ato de percepção" que Campbell usa no estudo do processo linguístico (Campbell, 1971, p. 9 apud Martino, 2007, p. 11).

Segundo Martino, a Estética da Comunicação não é uma estética preestabelecida, é uma estética percebida individualmente e leva em conta a percepção e a semiose de cada indivíduo participante deste processo. Trata-se de uma experiência estética produzida individualmente por meio dos processos de significação internos de cada indivíduo que entra em relação com a obra. Como ressalta Martino (2007, p. 12), "[a Estética Comunicacional] não pensa no uso da mensagem feita pelo sujeito, mas nas relações do sujeito no processo de comunicação".

O autor utiliza como exemplo de produção estética individual o publicitário que desenha um cartaz e mantém com ele uma relação pessoal, assim como o jornalista ao escrever um texto ou o radialista produzindo um programa. "Por mais mecanizado e rotineiro que seja o trabalho, o criador precisa pensar, imaginar, criar, e para isso comporta-se em uma relação pessoal com o objeto, mesmo que em um nível mínimo decorrente da repeti- ção da mesma atividade" (Martino, 2007, p. 12).

Essas mensagens, que são produtos da relação pessoal do criador com a obra, são recebidas pelo segundo agente da comunicação, o receptor, segundo Martino. No entanto, o receptor é dono de sua própria sensibilidade individual, segundo este pensamento, e também produz significação, completando o processo semiótico da comunicação estética. $O$ autor ressalta que:

Para a Estética da Comunicação não existe um momento de recepção de uma mensagem; mensagens circulam o tempo todo no espaço social; o indivíduo apropria-se delas, transforma-as, define-se com elas e através delas. $O$ indivíduo se define a partir de suas relações de comunicação, em sua sensibilidade (aisthesis) para organizar e reorganizar os fluxos contínuos de mensagens e se definir em relação a eles, bem como aos outros indivíduos, em uma seleção dos eventos comunicativos, dos signos, das mensagens. Nesse ponto, não se trata de uma nova teoria da recepção, mas em considerar a existência humana como um imenso percurso de significações presentes não apenas nas ações comunicativas, mas em todas as ações sociais (Martino, 2007, p. 9).

Martino sintetiza que, na estética comunicacional todo processo implica a relação entre uma produção e uma percepção. "Assim, a comunicação é uma estrutura móvel resultante dessa transformação dialética dos objetos do pensamento transmitidos/recebidos - em outras palavras, compartilhados - pelos sujeitos participantes" (Martino, 2007, p. 31).

Este intercâmbio de duas vias entre a obra e os interlocutores do processo comunicacional é essencial para entendermos o processo de comunicação que ocorre nos games. Segundo Martino (2007, p. 31) "o objeto do ato comunicativo nasce na necessidade de expressar algo para além de si mesmo". Portanto, pode-se entender que os jogos colocam o designer e o jogador em um ato comunicativo. A estética comunicacional se dá no ato comunicativo, envolvendo os participantes e a obra em uma teia aesthetica e cognitiva. Como aponta o autor, "o ato comunicativo não se pretende apenas o domínio do logos, mas também a comunicação de afetos, sentimentos, sensações. Há uma estética, portanto, em todo ato comunicativo" (Martino, 2007, p. 31).

Interessa aqui a citação que Martino tira de J. P. Fonseca, que cabe perfeitamente para interpretar a comunicação solitária que se dá entre o designer que implementa mecânicas e estéticas de um jogo e um jogador que, mesmo sem conhecer o seu interlocutor, experimenta a comunicação com o produto lúdico resultante:

Há um aspecto inelutavelmente denso na vivência estética. [...] Arma-se, de fato, uma comunicação entre intimidades, uma comunicação integral. A rigor conhecemos mais o estofo deste escultor, daquele romancista ou de um músico do que o do vago tio ou primo que apenas nos tangenciou o jogo da vida. A arte manifesta-se, assim, como um meio de romper a solidão (Fonseca apud Martino, 2007, p. 32, grifo do autor).

A aisthesis pode ser entendida como o começo de uma poiesis que se manifesta no interlocutor no processo comunicacional. "Uma comunicação é portanto, um ato estético na medida em que pretende externar, expressar para além de si mesmo e compartilhar, causando uma sensação similar em outro indivíduo" (Martino, 2007, p. 32) 
Podemos dizer, então, que o receptor, ou neste caso, o jogador, está imerso em um caldeirão de mensagens codificadas na estética do jogo e utiliza a sua própria sensibilidade para interagir com as mensagens que o jogo oferece durante a experiência de gameplay. Esta interação encontra força no conceito grego de estética (aesthesis), na qual a experiência (interação) do sujeito com o objeto é a base do fenômeno comunicacional que ocorre entre o jogador e o videogame. Para Martino (2007, p.15), este fenômeno é o centro do processo comunicativo justamente por escapar das categorias simples de análise como elementos isolados, mas focar-se na interação.

Entendemos até aqui que a estética dos games envolve um processo comunicacional pleno, através do qual o jogador exercita sua sensibilidade e se posiciona como elemento atuante desta relação. Porém, ao buscarmos a compreensão desse fenômeno, não podemos nos limitar somente à transmissão das mensagens. Existe um mundo de códigos no ambiente do jogo, e jogador e jogo são universos de signos dentro desse ambiente. $O$ diálogo entre esses dois universos, o afeto envolvido no processo e as significações cognitivas podem ser estudados pela semiose como uma epistemologia para entendermos as relações complexas entre jogo e jogador.

Nesse sentido, o conceito de signo triádico de Charles Sanders Peirce nos serve de maneira mais ampla, colaborando para compreender as interações entre máquina e jogo, jogo e jogador, e jogador e seu ambiente. Não somente os códigos e gráficos representados na tela do videogame são signos, mas o próprio jogador e o videogame o são. Como ressalta Peirce, "todo este universo é repleto de signos, se não o é composto exclusivamente de signos" (Peirce, 1906, p. 448). Para entender os signos e suas relações durante o ato do gameplay, precisamos entender o processo estético-comunicacional pelo qual os jogadores passam ao jogar um jogo.

\section{O ponto de vista semiótico nos games}

A Estética da Comunicação se difere da estética tradicional no sentido em que tenta entender o ser-no-mundo como um elemento em relação, ou seja, em comunicação. Ela foge do trinômio emissor-mensagem-receptor inspirado na Teoria Matemática da Comunicação, de Shannon e Weaver. Martino (2007, p. 13) nos fala que "O emissor e o receptor são sujeitos de um processo mais amplo do que ambos, ao mesmo tempo por ambos produzido e fora de seu controle direto". Para ele;

A Estética da Comunicação ganha terreno nos estudos de comunicação por sua perspectiva de derrubar algumas dicotomias neles presentes, por conta da separação, em compartimentos estanques, do emissor, da mensagem e do receptor, como se não fizessem parte do mesmo "mundo da vida" e esti vessem mergulhados no mesmo oceano de significados (Martino, 2007. p. 17).

A noção de "oceano de significados" remonta à concepção adotada para compreender a percepção na relação jogo-jogador. Em nossa perspectiva, a comunicação no ambiente de jogo está baseada não a partir do modelo sugerido pela teoria matemática da comunicação (emissão / mensagem / recepção), que pressupõe na mensagem uma codificação comum aos polos da emissão e da recepção, mas sim a partir da semiose. Buscamos o conceito de semiose no filósofo Charles Sanders Peirce. Segundo Peirce:
[.. .] por "semiose" quero significar (...) uma ação, ou influência, que é, ou envolve, a cooperação de três caracteres, quais sejam um signo, seu objeto e seu interpretante, não sendo tal influência trirrelacional de modo algum redutível a ações entre duplas. [Semiose], no grego do período romano, já na época de Cícero, se é que me lembro bem, significava a ação de quase todo tipo de signo; e minha definição confere o título de um "signo" a qualquer coisa que aja desse mesmo modo (Peirce CP 5.484).

Neste sentido, o signo faz parte da estética dos videogames, que em contato com a fronteira de percepção do jogador, promove uma significação posterior, completando o processo semiótico. Em Peirce: "Um signo, ou Representamen, é um Primeiro que está em uma tal relação genuína com um segundo, chamado seu Objeto, de modo que seja capaz de determinar um Terceiro, chamado seu Interpretante" (Peirce, CP 2.274).

Em sua pesquisa sobre a comunicação de crianças com os videogames, Pereira $(2008$, p. 397) dá grande ênfase ao conceito de interpretante de Peirce, pois este revela a semiose que a criança desenvolve ao entrar em contato com as linguagens do entretenimento. Apesar desse estudo se concentrar na aprendizagem infantil a partir da relação com os games, ele é válido para nosso artigo por se aplicar à relação entre o jogador e a máquina computacional para fins semiótico-comunicacionais. Em Peirce:

[...] um signo, ou representamen, é aquilo que, sob certo aspecto ou modo, representa algo para alguém. Dirige-se a alguém, isto é, cria, na mente dessa pessoa, um signo equivalente, ou talvez, um signo mais desenvolvido. Ao signo assim cria- 
do, denomino interpretante do primeiro signo (Peirce, CP 2.228).

Neste artigo, o conceito de semiose é combinado com a concepção de Estética da Comunicação de Martino para compreender a semiose envolvida na estética da comunicação do jogador com os videogames. Nesta perspectiva o jogador atua não somente como receptor, mas como agente pleno da comunicação. Como afirma Pereira:

A noção de que as mídias e suas linguagens exercem poderes determinantes no receptor em muito se deve à compreensão de que o receptor atua como agente passivo da comunicação, uma vez que desempenha o papel de decodificador das mensagens transmitidas pelas mídias, como se fosse um mero receptáculo de informações, incapaz de produzir novos sentidos para as mensagens recebidas. [...] Ante essa visão, que reduz a comunicação a um processo de ação e reação bastante previsível, tomamos como desafio desenvolver um ponto de vista teórico que pudesse revelar implicações nem sempre aparentes da comunicação infantil com os videogames e demais linguagens do entretenimento, tomando por base a dinâmica da semiose (Pereira, 2008, p. 398).

Utilizando o ponto de vista semiótico, percebemos que a comunicação de um indivíduo com uma forma cultural como o videogame mediada pela interação com os sistemas de signos experimentados durante o ambiente de jogo. Como conclui Pereira, "a aprendizagem semiótica que adquirimos com os videogames envolve a experiência, o sentir proporcionado pela imersão e par- ticipação na ação vivenciada [...] ao lidar com os códigos dos sistemas de signos que estruturam a narrativa" (Pereira, 2008, p. 409).

\section{Mecânicas, dinâmicas e estéticas de uma comunicação nos games}

Segundo a abordagem formal em relação à pesquisa e ao desenvolvimento de games proposta por Marc Leblanc, "a diferença entre games e outros produtos de entretenimento (como livros, músicas, e peças de teatro) é que a sua interação com o jogador é relativamente imprevisível. A sequência de eventos que se desenrolam durante o ato de jogar e o resultado destes eventos é desconhecido até a hora em que o produto é finalizado" (Leblanc, 2004, p. 3). Isto significa dizer que durante a concepção da narrativa os designers e roteiristas do jogo têm de desenvolver mecânicas que conversem com o jogador através das dinâmicas que este experimentará no jogo, que formará a estética narrativa perceptível ao gamer.
Leblanc descreveu o processo de comunicação nos games tanto pela perspectiva do jogador, quanto do projetista do videogame, utilizando uma variação da teoria matemática da comunicação de Claude Shannon entre mensagem-meio-receptor, porém com diferenças de design fundamentais, como pode ser visto no diagrama (Figura 1), no qual mecânicas seriam as regras do mundo de jogo criadas pelo designer, como pular, atirar, coletar itens. As dinâmicas seriam as diferentes possibilidades lúdicas resultantes dessas mecânicas e a estética a percepção que o jogador tem do produto final como obra. Da mesma forma, o jogador presencia a narrativa do jogo da direita para a esquerda, ou seja, primeiro é apresentado à estética do jogo, através de sua percepção das dinâmicas que foram criadas pelas mecânicas propostas pelo designer no momento da criação. Em suma, a comunicação acontece em uma via de mão dupla no qual tanto o designer comunica algo como o jogador comunica algo em resposta, diferenciando-se aqui do modelo sugerido pela Teoria Matemática pelo aspecto interativo dos games.

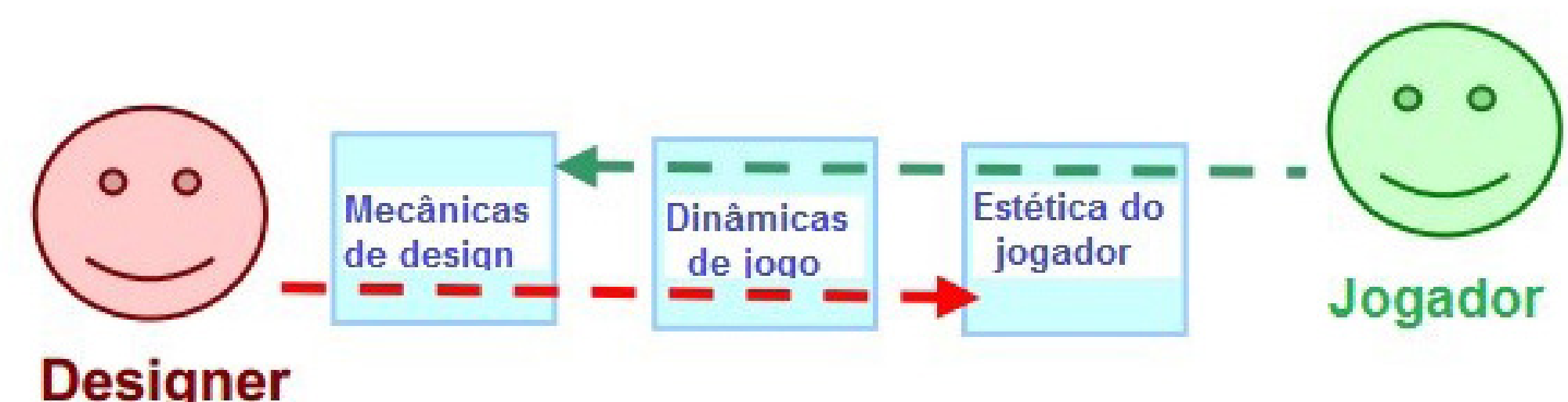

Figura 1: Fluxograma de produção e consumo de games segundo Leblanc (tradução livre). Fonte: Hunicke, R; Leblanc, M; Zubek, R, 2004. 
Marc Leblanc defende que o designer, ao tentar transmitir uma mensagem por meio de mecânicas lúdicas, precisa considerar que ela sofrerá uma transformação significativa, que incluirá a interação que o jogador terá com o jogo, isto é, sua percepção, ou estética, dentro das dinâmicas variáveis e imprevisíveis, que poderia ser entendida como ruído a partir da Teoria Matemática da Comunicação, mas que faz parte da comunicação que acontece durante o processo de gameplay. São essas mecânicas, dinâmicas e estéticas que formam as três partes do processo comunicacional dentro do jogo. $\mathrm{O}$ pesquisador defende que:

Da perspectiva do designer, as mecânicas geram comportamentos de sistemas dinâmicos, que por sua vez levam a experiências estéticas particulares. Da perspectiva do jogador, a estética estabelece o tom, que é criado a partir de dinâmicas de jogo observáveis e eventualmente mecânicas de operação. Quando trabalhamos com jogos, devemos considerar essas duas visões, tanto a do designer, quanto a do jogador (Hunicke, Leblanc, Zubek, 2004, p. 2).

Comunicacionalmente falando, o designer codifica algo através das mecânicas, que geram dinâmicas imprevisíveis e que por sua vez constroem a estética experimentada pelo jogador. Para Leblanc (2004, p. 1), especificamente em jogos eletrônicos, "análises iterativas, qualitativas e quantitativas ajudam o designer de duas maneiras importantes: ajudam a analisar o "resultado final para refinar a implementação" e "analisar a implementação para refinar o resultado final" (Leblanc, 2004, p. 1). Ao abordar o processo através dessas duas óticas, ele pode considerar vários níveis de possibilidades e interdependências:
Isto é especialmente importante ao se trabalhar com computadores e videogames, onde a interação entre os sistemas de códigos cria comportamentos complexos, dinâmicos (e por vezes imprevisíveis). Designers e pesquisadores devem considerar isso com cuidado antes de implementar mudanças, e acadêmicos devem reconhecê-las antes de tecer conclusões sobre a natureza da experiência gerada (Hunicke, Leblanc, Zubek, 2004, p. 1)

Dentro deste modelo, as mecânicas são os códigos de programação necessários para o game funcionar; as dinâmicas, o comportamento destas mecânicas aplicadas ao controle do usuário, e a estética da experiência vivida pelo jogador, quando ele interage com o sistema de jogo (ver Leblanc, 2004, p. 2).

Já vimos a estética sob o aspecto comunicacional (ver Martino, 2007) e a semiose que ocorre durante a jogabilidade dos games (ver Pereira, 2008), mas ainda nos falta definir gêneros de jogabilidade próprios ao videogame. Para Leblanc (2004, p. 2), ao definir a estética de um jogo, devemos nos distanciar de palavras como "diversão" e "jogabilidade" e nos mover em direção a um vocabulário mais específico. Isso inclui, mas não está limitado, os seguintes gêneros estéticos (ou sistemas codificantes): sensação, ou game como sentido de prazer; fantasia, ou game como faz-de-conta; narrativa, ou game como uma história; desafio, ou o jogo como uma pista de obstáculos; socialização, ou game como uma ferramenta social; exploração, ou videogame como um território a se descobrir; expressão, ou game como autodescoberta; e submissão, ou jogo como um simples passatempo.

Os jogos eletrônicos possuem centenas de sistemas de códigos, incluindo experiências estéticas aqui não listadas. Em teoria, a experiência que o jogador vivencia de um jogo é a estética que aquele jogo potencialmente oferece, e ao mesmo tempo, a sua semiose. Esses gêneros estéticos vão de contraponto às tradicionais classificações baseadas em mecânicas de jogo, tais como tiro, corrida, role-playing ou esporte. Entende-se que estas definições baseadas somente em mecânicas de jogo não são suficientemente fluidas para entender a estética única e pessoal que os games oferecem a cada jogador, e são baseadas em modelos de mercado direcionados a vender um produto específico a certo público. Leblanc ressalta que:

Enquanto não há uma teoria unificada de jogos ou fórmulas que detalhem a combinação e proporção de elementos que podem resultar em diversão, esta taxonomia nos ajuda a descrever a experiência dos jogos, direcionando uma luz na questão de porque diferentes games apelam para diferentes jogadores, ou aos mesmos jogadores em diferentes épocas (Hunicke, Leblanc, Zubek, 2004, p. 3).

As dinâmicas são a ponte comum entre o designer e o jogador. Elas são as ações que podem ser percebidas por ambos os lados do processo de comunicação no jogo, e são codificadas de forma a induzir o jogador a um estado estético específico. $\mathrm{O}$ autor usa como exemplo de dinâmicas de jogo as interações entre os vencedores e perdedores no jogo de tabuleiro Banco Imobiliário (Parker Brothers, 1903), (figura 2). Leblanc (2004, p.3) utiliza o exemplo de jogos do gênero de desafio, que possuem dinâmicas criadas para causar um estado de urgência no jogador, tais como limites de tempo para terminar uma fase ou oponentes agressivos; ou os de socialização, que pode ser promovida pela troca de in- 
formações entre membros de uma sessão de jogo, ou colocando desafios que seriam difíceis de serem superados sozinhos. Em outras palavras, todas as dinâmicas são implementadas de modo a induzir um estado de espírito específico no jogador.

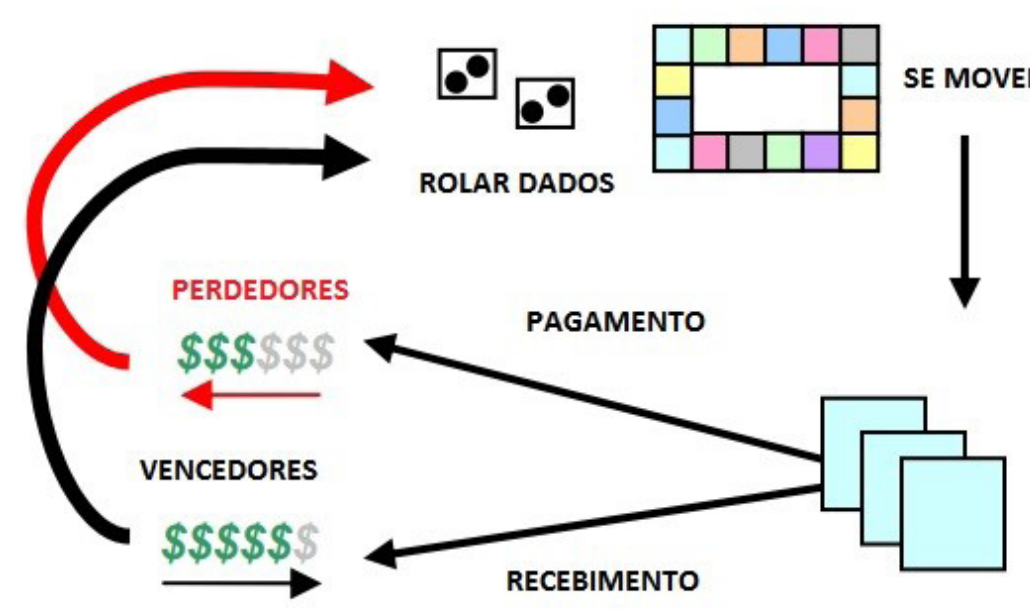

Figura 2: Dinâmicas de jogo do Banco Imobiliário (1903). Fonte: Hunicke, R; Leblanc, M; Zubek, R, 2004.

As mecânicas dos games são as várias possibilidades, comportamentos e mecanismos de controle que são codificadas como regras de um jogo. As mecânicas, junto ao conteúdo digital do game (fases, personagens, etc.) suportam as dinâmicas de gameplay. Leblanc $(2004$, p.5) utiliza como exemplo as mecânicas de jogos de cartas, como embaralhar, distribuir as cartas e apostas, de onde dinâmicas como o blefe podem surgir. As mecânicas de jogos de tiro incluem armas, munição e pontos de renascimento que, às vezes, produzem dinâmicas como emboscadas e assassinatos a distância. Ao conceber o design principal do jogo, o designer precisa levar estes três fatores em consideração para, de certa forma, manter um nível de controle sobre a experiência de usuário final que o jogador perceberá.

127 PORTO ALEGRE | v. 20 | n. 34 | 2015 | pp. 121-128 Sessões do Imaginário
Considerações finais

De acordo com o que vimos em Leblanc (2004), o formato de fabricação dos jogos permite certo controle do criador sobre a mensagem que o jogo pode transmitir em seu papel como uma nova experiência de mídia. No entanto, quem sempre vai definir a experiência narrativa final de um jogo é a própria interação que acontece entre o jogo e jogador, que pode resultar em efeitos totalmente inesperados, mas que ainda assim são fatores na comunicação estética entre esses atores. Podemos tomar como exemplo os arcades, que são dispostos em locais públicos onde a percepção do jogador é influenciado não só pela experiência do jogo mas pela experiência do local onde o jogo se encontra. Jogar um jogo em casa é diferente de jogá-lo em público. Os arcades adicionam o ambiente semiótico do lugar em que os jogos estão dispostos, criando uma nova experiência. $O$ mesmo pode ser dito sobre jogos em computadores ou consoles, ou jogos em celulares, que podem ser experimentos em qualquer lugar e incluem aí o ecossistema público a esta equação.

O que podemos concluir após a análise dessas formas complementares de estéticas comunicacionais no ambiente dos games é que a experiência do jogador é mediada pelos seus sistemas pessoais, influenciada pelas mecânicas projetadas pelo designer, mas que, ao mesmo tempo, o jogador também influencia a experiência do designer, que, ao construir o mundo de jogo tenta prever as ações dos jogadores e por meio de um sistema de códigos integrados à programação do game. O jogador torna-se, portanto, um signo para o designer, uma vez que este tenta prever as ações que serão desenvolvidas futuramente pelo seu interlocutor (o gamer). Neste sentido, o jogador e suas ações futuras se tornam representações sígnicas que mediam as estratégias do designer para a criação de um mundo de jogo.
Afinal, o receptor da mensagem, no ver semiótico e comunicacional, é agente atuante do processo. Portanto, influencia a criação de um artefato midiático como o videogame desde a sua concepção.

\section{Referências}

BRAS, Gérard. Hegel e a arte: Uma apresentação à estética. Rio de Janeiro: Jorge Zahar Editor, 1990.

CHAHI, Éric. Another World. [Videogame]. Desenvolvido por Delphine Software International, Interplay Entertainment, Magic Productions. Publicado por Delphine Software International. Paris, 1991. 1 CD.

DARROW, Charles, MAGGIE, Elizabeth. Monopoly. [Jogo de tabuleiro]. Desenvolvido por Parker Brothers. Distribuído por Hasbro. Atlantic City, New Jersey. 1903.

LEBLANC, Marc, et al. Mechanics, dynamics, aesthetics: A formal approach to game design. Palestra ministrada na Northwestern University, 2004. Disponível em: http://algorithmancy.8kindsoffun.com/MDAnwu.ppt. Acesso em: 10 jul. 2013.

KOJIMA, Hideo. Metal Gear. [Videogame]. Desenvolvido por Konami Japan. Publicado por Konami. Tokyo, Japão. 1987. 1 Disco.

MARTINO, Luiz Sá. Estética da comunicação: da consciência comunicativa ao 'eu' digital. São Paulo: Vozes, 2007.

PEIRCE, Charles Sanders. Collected Papers, In: The basis of pragmaticism, 1906. 
PEREIRA, Mirna Feitoza. Games e aquisição de linguagens: novas formas de sentir, pensar, conhecer. In: Estéticas tecnológicas: novos modos de sentir. São Paulo: Educ, 2008.

SHANNON, Claude. The mathematical theory of communication. Bell System Technical Journal, v. 27 pp. 379423, 1948.

\section{Notas}

1 Professora do Departamento de Comunicação e do Programa de Pós-Graduação em Ciências da Comunicação da Universidade Federal do Amazonas (Av. Gen. Rodrigo Octávio Jordão Ramos, 3000, Campus Universitário Coroado I, Manaus/AM, Brasil, CEP: 69077-000). E-mail:mirnafeitoza@gmail.com.

2 Mestrando no Programa de Pós-Graduação em Ciências da Comunicação da Universidade Federal do Amazonas (Av. Gen. Rodrigo Octávio Jordão Ramos, 3000, Campus Universitário Coroado I, Manaus/AM, Brasil, CEP: 69077-

000). E-mail: marcusascordeiro@gmail.com. 